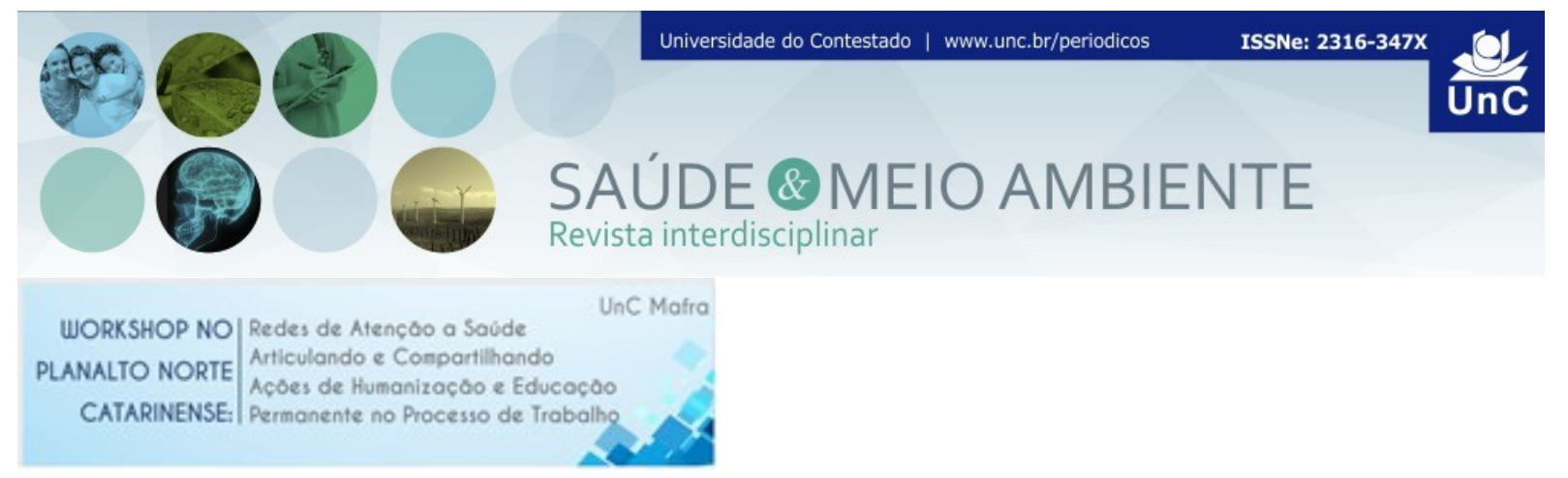

\title{
UTILIZANDO METODOLOGIAS ATIVAS PARA A EDUCAÇÃO PERMANENTE EM SAÚDE PARA QUALIFICAÇÃO DO PROGRAMA SAÚDE NA ESCOLA
}

\author{
Luciana Maria Mazon ${ }^{1}$ \\ Ariane Wohel $^{2}$ \\ Esvaldo Antunes ${ }^{3}$ \\ Sussane Stritzinger Cassias ${ }^{4}$ \\ Alexandre Engel $\left.\right|^{5}$ \\ Hellen Natali Correa Lagos Guimaraes ${ }^{6}$
}

\section{RESUMO}

INTRODUÇÃO: A Educação Permanente em Saúde (EPS) é uma proposta éticopolítico-pedagógica que visa transformar e qualificar a atenção à saúde, os processos formativos, as práticas de educação em saúde, além de incentivar a organização das ações e dos serviços numa perspectiva intersetorial (BRASIL, 2004). Nesse contexto as metodologias ativas surgem como proposta para focar o processo de ensinar e aprender na busca da participação ativa de todos os envolvidos, centrados na realidade em que estão inseridos. Como enfrentamento ao modelo tradicional imposto e aceito ao longo do tempo, tem-se lançado mão das metodologias ativas de ensino e aprendizagem, nas quais é dado forte estímulo ao reconhecimento dos problemas do mundo atual (tanto nacional quanto regional), tornando os sujeitos capazes de intervir e promover as transformações necessárias (OLIVEIRA; PONTES, 2011). OBJETIVOS: Descrever a experiência do Núcleo de Educação Permanente em proporcionar experiências de métodos não tradicionais de ensino aprendizagem aos profissionais de Atenção Básica em Saúde a fim de que pudessem empregá-las em seu cotidiano de trabalho junto ao Programa Saúde na Escola. MATERIAL E

\footnotetext{
${ }^{1}$ Enfermeira. Doutoranda em Saúde Coletiva/UFSC. Colaboradora da Secretaria Municipal de Saúde no Setor de Vigilância em Saúde e Docente da Universidade do Contestado Campus Mafra.

Integrante NEP/MAFRA. Santa Catarina. Brasil. E-mail: lucimazon@hotmail.com

${ }^{2}$ Assistente Social. Especialista em Gerenciamento de Unidades Básicas de Saúde; Especialista em Impactos da Violência na Saúde e em Gestão em Saúde Pública; Especialista em Gestão em Saúde Pública. Santa Catarina. Brasil.

${ }^{3}$ Enfermeiro. Mestre em Desenvolvimento Regional e Políticas Públicas/UnC. Coordenador do curso de Enfermagem e Docente da Universidade do Contestado campus Mafra. Integrante NEP/MAFRA. Santa Catarina. Brasil. E-mail: esvaldo@unc.br

${ }^{4}$ Farmacêutica. Mestranda em Saúde da Criança e do Adolescente/UFPR. Coordenadora do Núcleo de Apoio a Saúde da Família do município de Mafra/SC. Integrante NEP/MAFRA. Santa Catarina. Brasil. E-mail: susanne.cassias@gmail.com

${ }^{5}$ Enfermeiro. Especialista em Psicopatologia, psicanálise e saúde mental. Coordenador da Atenção Básica do Município de Mafra. Docente do Centro de Educação Profissional - CEDUP/Mafra. Integrante NEP/MAFRA. Santa Catarina. Brasil. E-mail: ale engel@outlook.com

${ }^{6}$ Fonoaudióloga. Mestre. Integrante do NASF e do NEP.Mafra. Santa Catarina. Brasil.
}

Saúde Meio Ambient. v. 6, n. esp. (Anais Workshop), p. 9-12, dez. 2017

ISSN 2316-347X 
Utilizando metodologias ativas para a educação permanente em saúde para qualificação do Programa Saúde na Escola

MÉTODOS: Trata-se de um Relato de Experiência da capacitação desenvolvida pelo NEP, estruturada nas metodologias ativas e direcionada aos profissionais de saúde atuantes na Atenção Básica em Saúde. A atividade aconteceu no ano de 2016 e envolveu aproximadamente 50 profissionais de saúde, incluindo dentistas, enfermeiros, técnicos de enfermagem e agentes comunitários de saúde. RESULTADOS: O NEP desenvolveu capacitações aos profissionais de saúde baseada nas metodologias ativas de Freire. Todas as atividades planejadas foram ricas em detalhes, tornando a capacitação atrativa e motivadora, para os profissionais de saúde. Desde o convite especial aos profissionais de saúde, sendo este criativo e colorido, assim como, as inscrições, onde cada Unidade Básica de Saúde (UBS) pode eleger seus participantes, que depois multiplicariam os conteúdos explorados. A programação do evento ficou estabelecida em período matutino e vespertino, em que cada participante inscrito poderia participar em até três Oficinas de 45 minutos cada uma. As atividades no período matutino envolveram: Dinâmica de Integração entre os participantes, denominada de "A parte mais Importante do Corpo", em que o objetivo era motivar a percepção dos participantes, de que somos seres diferentes e, sentimos o toque humano da maneira particular, muitas vezes conduzindo e outras vezes se deixando conduzir. Vivenciando a prática de Yoga. Nesta atividade foi proporcionada uma hora de prática de Yoga com profissional habilitado na área. O objetivo foi estimular a vivência do processo de conhecer-se, de buscar o equilíbrio mental e físico. Contextualizando PSE no Município de Mafra/SC. Nesta atividade foi apresentado de forma expositiva e dialogada os objetivos, a organização e abrangência do PSE no município de Mafra, pela Coordenação de Atenção Básica. As oficinas desenvolvidas no período vespertino, pela Equipe Multidisciplinar, foram tecidas, a partir de 15 minutos de bases teóricas problematizadas e 30 minutos de vivências com dinâmicas. Não foram utilizados equipamentos de projetor de multimídia, e os celulares dos participantes foram guardados em caixas coloridas no início de cada Oficina. As oficinas oferecidas foram: Oficina 1 - Direito sexual e reprodutivo e prevenção de IST/AIDS: Nesta atividade foi empregada a técnica de Cadeia de Transmissão. O Objetivo foi reconhecer comportamentos vulneráveis, identificar a cadeia de transmissão e refletir sobre a vivência sexual responsável. Oficina 2 - Prevenção ao uso de álcool, tabaco, crack e outras drogas: A oficina empregou a técnica "Desatando Nós", com o objetivo de refletir sobre os nós que o uso das drogas traz para a Vida das Pessoas e dos Familiares. Foram enfatizados ainda aspectos relativos a prevenção do uso de substância químicas e o impacto sobre a saúde física e mental. Oficina 3 - Promoção da cultura da Paz, Cidadania e Direitos Humanos: Nesta oficina, os participantes foram motivados a integrar Rodas de Conversa, a partir do Programa de Comportamento Moral, de Paula Inez Cunha Gomide (2010). Oficinas 4 - Promoção de segurança alimentar e nutricional saudável: Esta oficina envolveu um "Tabuleiro Nutritivo Gigante", em que as peças do tabuleiro eram os próprios participantes. O objetivo era por meio do jogo, estimular a percepção dos participantes diante os hábitos e costumes frente à alimentação saudável, bem como motivar as práticas de diferentes atividades físicas. Oficina 5 - Prevenção das Violências e dos acidentes: $O$ objetivo desta atividade foi trazer em cena a problemática das violências no contexto da saúde Pública. O método da atividade envolveu a encenação e a contação de histórias. O ambiente foi preparado com diversas fantasias (super-heróis, princesas, monstros, etc..). Os participantes foram convidados a vestir uma das fantasias e se posicionarem sentados em almofadas espalhadas na sala. A profissional mediadora da atividade iniciou o conto da história

Saúde Meio Ambient. v. 6, n. esp. (Anais Workshop), p. 9-12, dez. 2017 
do chapeuzinho vermelho, no entanto, o final desta história deveria ser dado por um desenho desenvolvido pelos participantes que envolvesse o personagem com o qual estavam caracterizados. $O$ desenho deveria ilustrar como a violência pode ser prevenida. Posteriormente os participantes foram convidados a dividir com o grupo seu desenho e ao contextualizar eram explorados aspectos relativos à violência. Oficina 6 - Promoção da Saúde e prevenção de doenças em eliminação: Nesta atividade o mediador expôs o que seriam os agravos em eliminação e as medidas profiláticas a serem adotadas para a promoção da saúde. Posteriormente os participantes foram convidados a participar de um jogo de tabuleiro, em que as peças eram os próprios participantes. O jogo se deu com perguntas e respostas, sendo que as respostas eram dadas coletivamente pelo grupo. A atividade proposta buscou além de proporcionar conhecimento básico sobre medidas profiláticas de doenças parasitárias e infecciosas, resgatar valores como união e solidariedade nos trabalhos em equipe. Oficina 7 - Promoção e avaliação de saúde bucal e aplicação tópica de flúor: Nesta atividade, foram apresentadas experiências exitosas desenvolvidas em ambientes escolares, que tiveram como recursos estratégicos, para mediar o diálogo entre Profissionais de Saúde a educandos, jogos, teatro com fantoches, desenhos e atividades cognitivas. Oficina 08 - Promoção da saúde, auditiva e identificação de educandos com possíveis sinais de alteração: Nesta oficina os participantes puderam vivenciar diferentes testes e percepções de avaliação da saúde auditiva. O método adotado foi uma roda de conversa, utilizando a dinâmica da batata quente para motivar um diálogo sobre o Posteriormente foram explorados testes simplificados de habilidades auditivas. CONCLUSÕES: A oficina de metodologias ativas, desenvolvida de forma multiprofissional e intersetorial, alicerçada no princípio teórico significativo da autonomia e no processo mútuo de ensinar e aprender permitiu instrumentalizar profissionais da atenção primária a saúde, para empregarem no Programa Saúde na Escola, novas metodologias, deixando um pouco de lado os tradicionais métodos com características marcantes de fragmentação e reducionismo.

Palavras-Chave: Ensino. Metodologias Ativas. Educação Permanente

\section{REFERÊNCIAS}

BRASIL. Portaria $n^{\circ} 198$ de 13 de fevereiro de 2004. Institui a Política Nacional de Educação Permanente em Saúde como estratégia do Sistema Único de Saúde para a formação e o desenvolvimento de trabalhadores para o setor e dá outras providências. Diário Oficial da União, 2004.

\section{GOMIDE, P. I. C. (Org.). Comportamento moral: uma proposta para o} desenvolvimento das virtudes. Curitiba: Juruá, 2010.

OLIVEIRA, M. G.; PONTES, L. Metodologia ativa no processo de aprendizado do conceito de cuidar: um relato de experiência. Anais... X Congresso Nacional de Educação - EDUCERE, Pontifícia Universidade Católica do Paraná, Curitiba, 2011. 
Utilizando metodologias ativas para a educação permanente em saúde para qualificação do Programa Saúde na Escola

Resumo recebido em: 12/12/2017

Resumo aprovado em: 17/12/2017

Resumo publicado em: 20/12/2017 